\title{
Predictive Validity of High-Resolution Ultrasonography as Compared to FNAC in Diagnosing Malignancy among Solitary Thyroid Nodules
}

\author{
D. Naveen ${ }^{1}$, K. Karthikeyan ${ }^{2}$ \\ ${ }^{1}$ Assistant Professor, Department of Radiodiagnosis, ${ }^{2}$ Assistant professor, Department of Radiodiagnosis, Dhanlakshmi \\ Srinivasan Medical College and Hospital, Siruvachur, Perambalur-621113, India
}

Corresponding author: Dr K. Karthikeyan, Assistant professor, Department of Radiodiagnosis, Dhanlakshmi Srinivasan Medical College and Hospital, Siruvachur, Perambalur-621113, India

DOI: http://dx.doi.org/10.21276/ijcmsr.2019.4.3.25

How to cite this article: D. Naveen, K. Karthikeyan. Predictive validity of high-resolution ultrasonography as compared to FNAC in Diagnosing malignancy among solitary thyroid nodules. International Journal of Contemporary Medicine Surgery and Radiology. 2019;4(3):C110-C113.

\section{A B S T R A C T}

Introduction: Ultrasound commonly used to evaluate lumps or nodules found during a routine physical or other imaging exam. Fine Needle Aspiration Cytology (FNAC) is also a commonly used method. Hence this study was conducted for the evaluation of thyroid lesion using high frequency ultrasound and correlates the results with fine needle aspiration cytology. Material and Methods: Prospective study of 75 patients with suspected solitary thyroid nodule referred from the Departments of Otorhinolaryngology, Medicine, Surgery, was performed in the Department of Radiologyand Imaging Sciences. Study period was December 2016 and September 2017 All 75 patients were subjected to an ultrasound examination of thyroid gland. Fine needle aspiration of the thyroid nodule was performed in all patients. FNAC was considered as gold standard and USG considered as screening test. The sensitivity, specificity, predictive values and diagnostic accuracy of the screening test along with their $95 \% \mathrm{Cl}$ were presented. $\mathrm{P}$ value $<0.05$ was considered statistically significant.

Results: Among the 18 lesions diagnosed as benign by FNAC, 5 (27.78\%) participants were identified as malignant and 13 $(72.22 \%)$ were identified rightly as benign by USG. The USG had had sensitivity of $100.00 \%$ in diagnosing malignant lesions as compared to FNAC. Specificity was $72.22 \%$, and the total diagnostic accuracy was $92.75 \%$.

Conclusion: Ultrasound findings and correlation with FNAC (fine Needle aspiration cytology) yields a better diagnosis. Hence, patient's management and outcome show satisfactory results.

Key words: FANC, High Frequency Ultrasound, Thyroid Lesions, Solitary Thyroid Nodule

\section{INTRODUCTION}

Thyroid nodules are often identified and project benign nature. Records of prevalence of nodular thyroid disease are seen depending on the participants examined and the techniques used to recognize nodules. Nodule incidence observed increasing as per age increases, in females population, iodine deficiency cases, and post radiation exposure. ${ }^{1}$ Thyroid nodule is described as an unusual growth of thyroid cells which leads to formation of lump within the thyroid gland. Majority of thyroid nodules being benign, a small proportion of thyroid nodules do contain thyroid cancer. ${ }^{2}$ The prevalence of thyroid nodules varies from $19 \%$ to $67 \%$ and increases with age, affecting about $50 \%$ of the population older than 40 years of age. ${ }^{3}$ estimations states that $5-10 \%$ of the population will develop a clinically significant thyroid nodule during their life-time. ${ }^{4}$ For diagnosis and treatment of thyroid cancer at the earliest stage, most thyroid nodules need some type of evaluation. $^{2}$

At beginning evaluation of any person suspected of having thyroid disease includes a clinical history, physical examination, and a variable number of laboratory investigations. Evaluation of the thyroid gland can be performed using various imaging techniques these modalities include plain radiography, radionuclide imaging, ultrasonography, CT, and MR imaging. ${ }^{5}$

Ultrasound (US) examination of the neck is a regularly performed investigation and thyroid nodules are among highly prevalent finding. Imaging features that confer a high positive predictive value and specificity for malignancy are valuable as they enable suspicious lesions to be identified and targeted for pathological analysis (typically fine-needle aspiration cytology, FNAC). ${ }^{6}$

Fine Needle Aspiration Cytology (FNAC) is an easy, rapid and low cost method used for sample superficial masses like those found in the neck and is generally carried out in the outpatient clinic set up. The trauma caused to the patient is less and carries virtually no risk of complications. Masses located within the region of the head and neck, including salivary gland and thyroid gland lesions can be readily diagnosed using this technique. ${ }^{7}$ The speedy diagnosis possible with fine needle aspiration helps to shorten or circumvent 
hospital admissions, and fasten a patient's route towards and appropriate specialist. In one previous study examining the impact of a FNAC service on the management of patients, findings were the savings exceeded the cost of the service by a factor of four. ${ }^{8}$

This study was done for the evaluation of thyroid lesion using high frequency ultrasound and correlates the results with fine needle aspiration cytology.

\section{MATERIAL AND METHODS}

Prospective study of 75 patients with suspected solitary thyroid nodule referred from the Departments of Otorhinolaryngology, Medicine, Surgery, was performed in the Department of Radiology and Imaging Sciences. This study was carried out between December 2016 and September 2017. All 75 patients were subjected to an ultrasound examination of thyroid gland. Fine needle aspiration of the thyroid nodule was performed in all patients. Asymptomatic / symptomatic patients detected to have Thyroid swelling on clinical examination were included in the study Physiological goitre was excluded from the study. Ultrasonogram of thyroid was done on Siemens Acuson Antares and Philips Envisor scanner with a $7.5 / \mathrm{MHz}$ flat probe, with the patient in the supine position with the neck extended. FNAC of the nodule was performed in the Department of Pathology and the smears sent for cytology. Ultrasonography diagnosis was correlated with the fine needle aspiration cytology report.

Descriptive analysis was carried out by mean and standard deviation for quantitative variables, frequency and proportion for categorical variables. The association between the two methods was assessed by cross tabulation and comparison of percentages. Chi square test was used to test statistical significance. FNAC was considered as gold standard. USG was considered as screening test. The sensitivity, specificity, predictive values and diagnostic accuracy of the screening test along with their $95 \% \mathrm{CI}$ were presented. $\mathrm{P}$ value $<0.05$ was considered statistically significant. IBM SPSS version 22 was used for statistical analysis.

\section{RESULTS}

A total of 75 subjects were included in the analysis. Majority (25.50\%) participants were aged between 11 to 20 years. The proportion of people in 41-50 years, 21-30 years, 5160 years, 61-70 years, 71-80 years and 11-20 years age group was $21.50 \%, 18.00 \%, 13.00 \%, 10.00 \%, 9.50 \%$ and $2.50 \%$ respectively. Among the study population, 13 (20\%) participants were male remaining $62(80 \%)$ participants were female. (Table 1)

All the participants had swelling in the neck, followed by Dysphagiain $9 \%$ and pain and hoarseness of voice among $8 \%$ each respectively. Among the study population, 30 (40\%) participants had right lobe, 28 (37.33\%) participants had left lobe, 18 (24\%) participants had both lobe and only $1(1.33 \%)$ participant had isthmus involvement. (Table 2)

Among the study population, 51 (68\%) participants had benign, 18 (24\%) participants had malignant lesions on FNAC. Four (5.3\%) participants had Inadequate Material. Among the benign lesions, $32(46.50 \%)$ participants had Goitre with cystic changes, $10(14.50 \%)$ participants had

\begin{tabular}{|l|l|l|}
\hline Age & No. of cases & Percentage (\%) \\
\hline $11-20$ & 2 & $2.50 \%$ \\
\hline $21-30$ & 13 & $18.00 \%$ \\
\hline $31-40$ & 21 & $25.50 \%$ \\
\hline $41-50$ & 16 & $21.50 \%$ \\
\hline $51-60$ & 10 & $13.00 \%$ \\
\hline $61-70$ & 7 & $10.00 \%$ \\
\hline $71-80$ & 6 & $9.50 \%$ \\
\hline Gender & 13 & $20.00 \%$ \\
\hline Male & 62 & $80.00 \%$ \\
\hline Female & 2 & \\
\hline Table-1: Baseline characteristics of the study population \\
\multicolumn{2}{|c|}{$(\mathrm{N}=75)$} \\
\hline
\end{tabular}

\begin{tabular}{|l|c|c|}
\hline Parameter & Frequency & Percentage (\%) \\
\hline Clinical presentation & & \\
\hline Dysphagia & 7 & $9.00 \%$ \\
\hline Swelling in the neck & 75 & $100.00 \%$ \\
\hline Pain & 6 & $8.00 \%$ \\
\hline Hoarseness of voice & 6 & $8.00 \%$ \\
\hline Weight loss & 2 & $2.50 \%$ \\
\hline Menstrual irregularities & 2 & $2.50 \%$ \\
\hline Palpitation & 1 & $1.50 \%$ \\
\hline Dyspnoea & 1 & $1.50 \%$ \\
\hline Location & 30 & $40 \%$ \\
\hline RIGHT LOBE & 28 & $37.33 \%$ \\
\hline LEFT LOBE & 18 & $24 \%$ \\
\hline BOTH & 1 & $1.33 \%$ \\
\hline ISTHMUS & \multicolumn{2}{|c|}{} \\
\hline Table-2: Clinical characteristics of solitary thyroid nodule in the \\
\hline \multicolumn{2}{|l|}{ study population } \\
\hline
\end{tabular}

\begin{tabular}{|l|l|l|}
\hline FNAC Findings & Frequency & Percentage (\%) \\
\hline Type of Nodule & 51 & $68 \%$ \\
\hline Benign & 18 & $24 \%$ \\
\hline Malignant & 4 & $5.3 \%$ \\
\hline Inadequate Material & 2 & $2.6 \%$ \\
\hline FNAC not done & \multicolumn{2}{|l|}{} \\
\hline TYPE OF BENIGN LESION \\
\hline Goitre with cystic changes & 32 & $46.50 \%$ \\
\hline Cystic lesion & 10 & $14.50 \%$ \\
\hline Adenoma & 4 & $8.50 \%$ \\
\hline Thyroiditis & 4 & $6.00 \%$ \\
\hline Abscess & 1 & $1.50 \%$ \\
\hline Type of malignant lesions & 12 & $17 \%$ \\
\hline PAPILLARY CA & 5 & $7 \%$ \\
\hline FOLLICULAR CA & 1 & $1.5 \%$ \\
\hline ANAPLASTIC &
\end{tabular}

Table-3: Incidence of various benign and malignant lesions of FNAC ( $=75)$

Cystic lesion, 4 (8.50\%) participants had Adenoma and 4 (6\%) participants had Thyroiditis. Among the malignant lesions, 12 (17\%) participants had papillary CA and 5 (7\%) participants had follicular CA. (Table 3)

All the malignant lesions on FNAC, were identified as 


\begin{tabular}{|l|l|l|l|l|}
\hline \multirow{2}{*}{ US } & FNAC & \multirow{2}{*}{ Chi square } & \multirow{2}{*}{ P value } \\
\cline { 2 - 3 } & Malignant (N=51) & Benign (N=18) & & \multirow{2}{*}{45.384} \\
\hline Malignant & $51(100 \%)$ & $5(27.78 \%)$ & & \\
\hline Benign & $0(0 \%)$ & $13(72.22 \%)$ & \\
\hline *6 cases for which FNAC not done/ inadequate sample were excluded from the analysis \\
\hline \multicolumn{2}{|l|}{ Table-4: Association between USG and FNAC findings among the study population } \\
\hline
\end{tabular}

\begin{tabular}{|l|c|c|c|}
\hline \multirow{2}{*}{ Parameter } & \multirow{2}{*}{ Value } & \multicolumn{2}{|c|}{ 95\% Cl } \\
\cline { 3 - 4 } & & $93.02 \%$ & Upper \\
\hline Sensitivity & $100.00 \%$ & $46.52 \%$ & $90.00 \%$ \\
\hline Specificity & $72.22 \%$ & $9.69 \%$ & $90.31 \%$ \\
\hline False positive rate & $27.78 \%$ & $0.00 \%$ & $53.48 \%$ \\
\hline False negative rate & $0.00 \%$ & $80.38 \%$ & $6.98 \%$ \\
\hline Positive predictive value & $91.07 \%$ & $75.29 \%$ & $97.04 \%$ \\
\hline Negative predictive value & $100.00 \%$ & $83.89 \%$ & $100.00 \%$ \\
\hline Diagnostic accuracy & $92.75 \%$ & $97.61 \%$ \\
\hline \multicolumn{2}{|c|}{ Table-5: Predictive validity of USG against FNAC (Gold standard) } \\
\hline
\end{tabular}

malignant on USG examination. Among the 18 lesions diagnosed as benign by FNAC, 5 (27.78\%) participants were identified as malignant and $13(72.22 \%)$ were identified rightly as benign by USG. (Table 4)

The USG had had sensitivity of $100.00 \%$ (95\% CI 93.02\%to $100.00 \%)$ in diagnosing malignant lesions as compared to FNAC. Specificity was $72.22 \%$ (95\% CI 46.52\%to 90.31\%), false positive rate was $27.78 \%(95 \%$ CI $9.69 \%$ to $53.48 \%$ ), false negative rate was $0.00 \%(95 \%$ CI $0.00 \%$ to $6.98 \%)$, positive predictive value was $91.07 \%$ (95\% CI $80.38 \%$ to $97.04 \%$ ), negative predictive value was $100.00 \%$ (95\% CI $75.29 \%$ to $100.00 \%)$, and the total diagnostic accuracy was $92.75 \%(95 \%$ CI 83.89\%to 97.61\%). (Table 5)

\section{DISCUSSION}

The use of high-resolution ultrasound is commonly preferred method for the evaluation of thyroid size and morphology. ${ }^{9}$ In our study out of 75 participants 62 were females and the age group which dominated the most was $31-40$ years. Present study showed 30 cases located in right lobe while only 1 case was in isthmus. A study done to analyze the risk of malignancy of nodules depending on location has emerged with conclusion stating mid-lobar nodules had higher risk of thyroid malignancy. ${ }^{10} \mathrm{~A}$ case report and review of literature results commented that the isthmus location could be an additional risk factor to consider for a correct surgical approach in indeterminate thyroid lesions and thyroid cancer at fine-needle aspiration (FNA). ${ }^{11}$ In a study Thyroidectomy performed in 1,973 thyroid cancer patients showed that papillary thyroid carcinomas located in the isthmus was more likely to be associated with multiple foci in bilateral lobes and higher rates of capsular invasions than tumours in other thyroid regions. ${ }^{12}$

A cross sectional study done in Bangladesh gave results that among 188 study subjects 24 found with histologically thyroid malignancy. ${ }^{13}$ A study which was performed on 141 patients with true solitary thyroid nodules undergoing bilateral total thyroidectomy reported irregular borders, microcalcification, increased vascularity, and detection of cervical lymphadenopathy were found to be correlated with malignancy in solitary nodules. ${ }^{14}$ Present study gave us finding that $68 \%$ of population had benign lesions incidence with solitary thyroid nodule.One study showed that Solitary Nodule of Thyroid was more common in female participants with incidence of Malignancy of $8 \% .{ }^{15}$

In our present study findings we discovered $100 \%$ of the population having swelling in neck as a clinical feature presented with solitary thyroid nodule while palpitation and dyspnoea were least observed. Our findings matched the conclusion given by a case study of solitary thyroid nodule. ${ }^{16}$ A comparative study gave similar findings where solitary thyroid group was having neck swelling among majority of the study participants. ${ }^{17}$

In our study all malignant lesions on FNAC, were identified as malignant on USG examination.Previously done investigation stated that High-resolution thyroid ultrasonography is a dynamic tool for endocrinologists. ${ }^{18}$. A research concluded that Preoperative neck US is a valuable tool in the detection of cervical lymph node metastases from papillary thyroid cancer and can provide reliable information to assist in surgical management. ${ }^{19} \mathrm{An}$ investigation reported that precise ultrasonographic-guided aspiration, strict adherence to guidelines for adequacy of the sample, proper cytologic preparation, and most importantly, expert cytologic analysis, a diagnosis of benign is extremely reliable for thyroid nodules, regardless of size. ${ }^{20}$ Another study concluded that Sonographically guided fine-needle aspiration biopsy of neck masses has a high sensitivity (91\%) and should be routinely used to evaluate indeterminate masses in neck. ${ }^{21}$ Our results stated that the USG had sensitivity of $100.00 \%$ in diagnosing malignant lesions as compared to FNAC and Specificity was $72.22 \%$ with total diagnostic accuracy $92.75 \%$.

\section{CONCLUSION}

Using high frequency ultrasound is an ideal imaging technique for characterizing solitary thyroid nodules due to its superior anatomical resolution. Above all, it is safe because of its non-invasive nature and lack of ionizing radiation. Ultrasound findings and correlation with FNAC (fine Needle aspiration cytology) yields a better diagnosis. 
Hence, patient's management and outcome show satisfactory results.

\section{REFERENCES}

1. Dean DS, Gharib H. Epidemiology of thyroid nodules. Best Pract Res Clin Endocrinol Metab. 2008;22(6):90111.

2. Thyroid Nodules | American Thyroid Association [Internet]. American Thyroid Association. 2019 [cited 23 May 2019]. Available from: https://www.thyroid. org/thyroid-nodules/ [

3. Cosgrove D, Barr R, Bojunga J, Cantisani V, Chammas MC, Dighe $M$, et al. WFUMB guidelines and recommendations on the clinical use of ultrasound elastography: Part 4. Thyroid. Ultrasound Med Biol. 2017;43(1):4-26.

4. Zeiger MA, Prasad NB, Libutti SK, Umbricht CB. Diagnostic tool for diagnosing benign versus malignant thyroid lesions. Google Patents; 2016.

5. Hegedüs L. Thyroid ultrasound. Endocrinol Metab Clin North Am. 2001;30(2):339-60.

6. McQueen AS, Bhatia KS. Thyroid nodule ultrasound: technical advances and future horizons. Insights Imaging. 2015;6(2):173-88.

7. Ahmad T, Naeem M, Ahmad S, Samad A, Nasir A. Fine needle aspiration cytology (FNAC) and neck swellings in the surgical outpatient. J Ayub Med Coll Abbottabad. 2008;20(3):30-2.

8. Roskell DE, Buley ID. Fine needle aspiration cytology in cancer diagnosis. British Medical Journal Publishing Group; 2004.

9. Guth S, Theune U, Aberle J, Galach A, Bamberger C. Very high prevalence of thyroid nodules detected by high frequency $(13 \mathrm{MHz})$ ultrasound examination. Eur J Clin Invest. 2009;39(8):699-706.

10. Ramundo V, Lamartina L, Falcone R, Ciotti L, Lomonaco C, Biffoni M, et al. Is thyroid nodule location associated with malignancy risk? Ultrasonography. 2019;38(3):231.

11. Pontieri G, Urselli F, Peschi L, Liccardi A, Ruggiero A, Vergara $\mathrm{E}$, et al. Is the isthmus location an additional risk factor for indeterminate thyroid nodules? Case report and review of the literature. Front endocrinol. 2018;9:750

12. Lee YS, Jeong JJ, Nam KH, Chung WY, Chang HS, Park CS. Papillary carcinoma located in the thyroid isthmus. World J Surg. 2010;34(1):36-9.

13. Rashid MS, Akhter N, Rahman MS, Majumder JA, Delwar A, Mustafa MG. Frequency of Malignancy in Solitary Thyroid Nodule in a Tertiary Level Hospital of Bangladesh. Int J Otorhinolaryngol Head Neck Surg. 2019;8(04):132.

14. Uyar O, Cetin B, Aksel B, Dogan L, Beksac K, Akgul GG, et al. Malignancy in Solitary Thyroid Nodules: Evaluation of Risk Factors. Oncol Res Treat. 2017;40(6):360-3.

15. Musthafa SM, Mahadevan D, Daniel R, Rai R, Vallal DP, Reddy ML, et al. Clinical and histopathological profile of patient with solitary thyroid nodule in tertiary care hospital in South India. J Evol Med Dent Sci. 2017;6(89):6196-200.
16. Shashikala V, Muralidhar A, Kuchinoor A, Suntan A. A clinical study of solitary nodule thyroid. Int Surg J. 2019;6(3):754-8.

17. Krishna MBM, Yajamanam N. Comparative study of various thyroid disorders in patients with solitary thyroid nodule and multi-nodular goitre. Indian J Appl Res. 2019;9(6).

18. Mandel SJ. Diagnostic use of ultrasonography in patients with nodular thyroid disease. Endocr Pract. 2004;10(3):246-52.

19. Abboud B, Smayra T, Jabbour H, Ghorra C, Abadjian G. Correlations of neck ultrasound and pathology in cervical lymph node of papillary thyroid carcinoma. Acta Chir Belg. 2019:1-7.

20. Porterfield JR, Jr., Grant CS, Dean DS, Thompson GB, Farley DR, Richards ML, et al. Reliability of benign fine needle aspiration cytology of large thyroid nodules. Surgery. 2008;144(6):963-8; discussion 8-9.

21. Boland GW, Lee MJ, Mueller PR, Mayo-Smith W, Dawson SL, Simeone JF. Efficacy of sonographically guided biopsy of thyroid masses and cervical lymph nodes. AJR Am J Roentgenol. 1993;161(5):1053-6.

Source of Support: Nil; Conflict of Interest: None

Submitted: 29-07-2019; Accepted: 16-08-2019; Published online: 26-08-2019 